\title{
Migration and Sexual Health Among Gay Latino Migrants to Canada
}

\author{
BARRY D ADAM \\ J CRISTIAN RANGEL
}

Abstract. This paper enquires into the nexus of migration with sexual health among gay Latino migrants in Canada. Interviews with 25 Spanish-speaking interviewees are examined in light of models developed from studies of Latinos in the United States. Canadian immigration policy appears to result in a somewhat different selection of immigrants compared to the United States. Migrants come from a wide range of national and regional backgrounds intersected by race, generation, and social class that influence their perceptions of and adjustment to Canadian society. Pre-migration HIV knowledge varied strongly by generation with older men recalling public panic concerning HIV and younger men receiving formal education about it. Migration enters into the mix of conditions as kin ties can be less confidently relied on among gay men compared to their heterosexual counterparts and by exacerbating vulnerability among those seeking to develop new social and sexual networks.

Keywords: Latino, men who have sex with men; gay men; migration, sexual health; HIV risk; Canada

Résumé. Cet article examine le lien entre la migration et la santé sexuelle, chez les migrants gais latinos au Canada. Des entrevues avec 25 répondants hispanophones sont examinées à l'aide de modèles développés dans le cadre de recherches réalisées aux États-Unis au sujet des Latinos. Les politiques canadiennes en matière d'immigration semblent aboutir à une sélection d'immigrants qui diffère de celle des États-Unis. Les migrants présentent une grande variété d'origines nationales et régionales, croisées des facteurs de race, de génération et de classe sociale qui influencent leurs perceptions de la société canadienne et leur adaptation à celle-ci. La connaissance du VIH avant la migration varie fortement selon la génération : les hommes plus âgés se souviennent de la panique publique au sujet du VIH, alors que les plus jeunes ont reçu une éducation formelle concernant le VIH. La migration vient s'ajouter à la mosaïque de facteurs en cause, notamment parce que les connexions à la parenté ne constituent pas une option de soutien aussi fiable pour les hommes gais que pour leurs homologues hétérosexuels, et également en raison de l'exacerbation de la vulnérabilité parmi 
ceux qui cherchent à développer de nouveaux réseaux sociaux et sexuels.

Mots clés: Le latin, les hommes qui ont des rapports sexuels avec des hommes; les hommes gais; Migration, santé sexuelle; Risque de VIH; Canada

\section{INTRODUCTION}

Or almost two decades, researchers in the United States have been inquiring into the sexual health of Latino gay, bisexual, and other men who have sex with men, largely looking for possible explanations for persistently elevated rates of HIV among Latinos compared to the overall population (Gonzalez et al. 2009; Centers for Disease Control and Prevention 2017). With a much smaller Spanish-speaking population and only episodic data collection on HIV rates by ethnicity, the evidence is more limited concerning Latinos in Canada but there is some indication that a similar pattern may exist (Myers et al. 2011; Ontario HIV Epidemiology and Surveillance Initiative 2017). There are also several reasons to believe that Latino communities in Canada may vary significantly from those in the United States. Canada has a distinctive history of immigration policy that tends to select the healthiest, wealthiest, and most educated; it also has a smaller and more recent Latino community. The overall pattern of countries of origin of Latino migrants varies somewhat from the US profile. As well, included here are many men who have been born after the height of the HIV epidemic (1980s and 1990s) and so have different coming-of-age experiences (Hammack and Cohler 2011) than many of the participants who have been included in the research literature to date.

This study enquires into the ways in which migration and sexual health may be associated among gay Latino migrants by examining the pre-migration context of coming of age, family, and HIV information in home countries. Study participants characterize sexual relationships between men in their home countries, the social climate in which they occur, and their intersection with family and work life. They describe how these relationships are socially organized, whether gay scenes existed in their social environment, their relationships to these scenes, and awareness of, and information received about, HIV in the home country. Furthermore, interview narratives address the disruption and redevelopment of social networks through the migration process, having a lot to say about how sexuality affected the ability to rely on family networks that have often proved to be critical resources in the narratives of non-gay migrants. Finally, they comment on challenges encountered 
in forming new relationships in Canada and in managing HIV risk in a new social context.

\section{Migration and Gay, Lesbian, Bisexual, and Transgender (LGBT) People}

While a good many migration studies focus on the stressful and disruptive effects of migration and their apparently negative outcomes on health, it is worth keeping in mind that migration is not only a story of loss. Anne-Marie Fortier (2001) and Larry Knopp (2004) point out persuasively the problematic nature of the discourse of home in much migration narrative as LGBT people not infrequently find themselves in families and neighbourhoods of origin that are unfriendly, if not hostile, to their sexual expression and desire for intimacy. For many, migration may be less about loss of home, than a quest for home, in that they may long for or search for more hospitable environments where they can love and live with a person of their choice, or simply to be left free from harassment or deprecation. Andrew Gorman-Murray's (2009) study of LGBT migration inside Australia found that many moved for the opportunity to reinvent themselves outside of hetero-normativity and to find partners, be near a gay-friendly neighbourhood, or consolidate a same-sex relationship. In a study of migration inside Canada and the United States, Nathaniel Lewis (2014) found interviewees to be on the whole "happier after moving and the majority reported improved overall health, higher self-esteem and less sadness."

Migration, then, may involve movement inside and across national boundaries. Some migrants arrive in northern countries having already been internally displaced in their countries of origin due to political or homophobic violence (Zea et al. 2013). In terms of the historical trajectory of Western societies, LGBT people have often been cut adrift from their communities and families of origin, either through "push" factors such as family or community disapproval, or through "pull" factors of migration to friendlier social settings.

\section{Migration and Sexual Health}

Despite these motivations and potential benefits, there is a good deal of evidence of the disruptive effects of migration particularly on health. While immigrants typically arrive in Canada with indicators of better overall health than the host population, over time their health status appears to decline toward national medians (Newbold 2006). The decline 
of the "healthy migrant" appears to be strongest among those who encounter particular difficulties in the host country. Analysis of the Canadian Community Health Survey shows "that visible minorities and immigrants who experienced discrimination or unfair treatment are most likely to experience a decline in self-reported health status and.... a clear inverse socioeconomic gradient exists with respect to increasing levels of self-reported mental health problems" (De Maio and Kemp 2010).

Despite the benefits of migration, the declining health of long term migrants and the apparent association of migration with increased vulnerability to HIV have led several researchers to propose a connection between migration-linked disruptions of social relations and increased HIV risk (Magis-Rodríguez et al. 2009; Organista et al. 2004; Poppen et al. 2005; Carrillo 2004; Bruce et al. 2011). Based on research with gay men in south Florida, James Egan and colleagues (2011) argue that

this increased vulnerability is related to the losses of close family relationships, established social and sexual mores, and years of social capital built up within the home community that occur upon migration.... [T]he urban subcultures to which men migrate are somewhat limited in their capacity to be supportive because MSM [men who have sex with men] bring their inherited masculinity norms, internalized homophobia, and histories of victimization - all aspects of the syndemic affecting MSM health — to this new, less-structured social realm.

The social disruption thesis is reinforced by research showing that social attachment indicators, whether to Latino or gay communities, can act as protective factors in HIV risk (O'Donnell et al. 2002; Althoff et al. 2013; Ramirez-Valles et al. 2010).

Increased HIV risk may in part be a function of simply searching for new social and sexual connections in new environments. A major study of gay male migration within Europe found migrants were likely to have more partners compared to non-migrants and "feel disconnected from others and/or lack a sense of community with other men who have sex with men" (EMIS Network 2013). The search for new contacts, partners, and friends may include "exposure to new, unfamiliar and sometimes risky micro-communities" (Lewis 2014) such as drug-using networks (Egan et al. 2011). A good deal of HIV risk may lie in tacit miscommunication about the meaning of condomlessness in new sexual environments, potentially exacerbated by differences in cross-cultural assumptions (Fontdevila 2009; Adam et al. 2008). 


\section{LATINOS AND RisK}

A strength of the research literature on Latino men has been its sensitivity to social context, as the larger study of HIV has tended to typify gay men as individual "men who have sex with men" acting as rational or irrational calculators of risk without much regard to the structures of gay worlds, family, work, and social expectations. All the same, migration is not necessarily an overriding factor. Latino men, like other gay men, show considerable variation in risk practice with most men having sex with condoms most of the time. A good deal of research on gay men and HIV risk has cumulated evidence for a few particularly salient precursors to HIV vulnerability that have a multiplicative effect when occurring together. The identification of these syndemic factors (Stall et al. 2007) has led to research on what coping strategies may show resilience to risk precursors. While there is increasing evidence that childhood trauma, interpersonal violence, depression, or substance use are associated with later HIV risk and other health problems, there is no clear evidence that these precursors occur more often among Latino men. Early work that focused on childhood sexual abuse as the source of childhood trauma has since extended into work on homophobic and racist bullying, an area of potentially heightened vulnerability for Latino men. Both homophobic and racist bullying do show statistical association with unprotected sex among Latino men (Nakamura and Zea 2010; Ryan et al. 2009; Díaz et al. 2001; Díaz et al. 2004). In an in-depth investigation of these issues, Sonya Arreola and colleagues (2013) note that "for Latino gay men, to the extent that social structures limited a sense of agency during sexual development in childhood, a reduced sense of agency continued into adulthood, reinforcing a sense of reduced choice and will over sexual encounters." Complicating the usual definition of childhood sexual abuse that typically equates all sexual contact below the age of sixteen with abuse, this study found that voluntary youthful sexual exploration actually improved later resiliency and well-being. Both supportive family members and same-age or older men discovered through sexual exploration contributed to "a sense of self and a quality of agency when describing both their childhood and adult sexual episodes, even in the face of virulent homophobic environments."

More difficult to assess is the proposition that certain cultural beliefs circulating in Latino communities may increase HIV risk. Rafael Díaz (1998) has argued that cultural silence about sexuality, low identification with gay communities, and reliance on "down low," hidden, or fleeting encounters with other men, plus persistent beliefs in fatalism and in the uncontrollability male passion, can contribute to heightened HIV risk. 
An emergent research literature offers some preliminary evidence that beliefs of this type do correlate with higher risk sexual practices (Lo et al. 2011; Muñoz-Laboy et al. 2005).

\section{This Study}

This study arises out of discussions among researchers and frontline workers in gay men's sexual health with an interest in, or mandate to serve, Spanish and Portuguese speaking populations. This group designed the Cuéntame study which conducted a web survey followed by in-depth interviews with Latino gay men through a community-based research project organized and directed by a team of Spanish- and Portuguese-speaking community workers and researchers with an interest in improving sexual health interventions (Betancourt 2011; Adam et al. 2011).

Use of a term like Latino immediately raises a question of who may or may not be included in such a category and how meaningful it may be to those who are. The term is scarcely uncontested in the United States where it enjoys greatest currency (Pérez 2011). In Canada, it may need to be treated with even greater caution where the bulk of Latino presence is relatively recent and many retain affiliation to their country of origin without necessarily feeling an overarching connection to a common Latino community. The community-based team of gay Spanish speaking men who organized this study ultimately settled on a criterion for inclusion in the study by operationalizing Latino as a man who is Spanishspeaking or comes from Spanish-speaking origins, and has had sex with a man in the last year.

Any characterization of "Latino" migration experience needs to take account of the heterogeneity of social locations from which migrants originate (Cantu 2009; Carrillo 2004) and pre-migration experiences can be shaped by a wide range of social conditions defined by social class, race, generation, nation, and region. We then explored these same issues post-migration to see how study participants view sexual relationships between men in Canada and the social climate around them, whether they participate in local gay scenes, and the impact of migration on their sexual identity and relationships. Questions of motivation to emigrate, sexual citizenship, social capital, and immigration challenges, also investigated in this study, are reported elsewhere (Lewis 2016; Adam and Rangel 2015). 


\section{Methodology}

This study was carried out in Canada's largest metropolitan area containing the largest concentration of Spanish-speaking people in the country. Because of this siting, Latino migrants arrive primarily through regular immigration channels, including the skilled worker, family reunification, refugee, and asylum programs but not through the temporary migrant farm worker program which is located in rural areas (Basok 2004). Latino migrants enter a city where one half of residents are foreign born and where 47 per cent of the population identify themselves as part of a visible minority. Overall, Latin Americans make up 117,005 or 2.1 per cent of the city population (Statistics Canada 2017).

Latino gay, bisexual, and other men who have sex with men are largely an unorganized, "hidden" population; there is no systematic or straightforward way to access them for participation in a study. From respondents to the web survey which was circulated by the Centre for Spanish Speaking People and through the social networks of the community workers and their agencies associated with this study, potential study participants were identified through purposive sampling to include a diversity of nationalities, ages, social class backgrounds, and immigrant statuses. Twenty-five interviews were then conducted in Spanish by a graduate student in sociology who was a Mexican national attending a Canadian university.

Interviews were conducted at the Centre for Spanish Speaking People or a location chosen by the interviewee; they typically lasted an hour and a half. The study was reviewed by the University of Windsor in accord with the Tri-Council Policy Statement: Ethical Conduct for Research Involving Humans. Study participants were offered \$30 in compensation for their time and travel. Study participants were asked questions in semi-structured interviews about pre- and post-migration perceptions of same-sex relationships and scenes, kin ties and support, HIV knowledge, and reflections and practices related to managing HIV risk. Interviews were subsequently transcribed and narratives were coded by question, then grouped into thematic areas using NVivo10. The current analysis draws on themes focused on: the context of migration, LGBT rights and cultures in country of origin, migration as transition, HIV knowledge, and HIV risk management. Each theme then was examined for more specific topics, and narratives were sorted into a spectrum of responses for each topic area through constant comparative analysis. 


\section{DEMOGRAPHICS}

The twenty-five study participants showed the following characteristics:

- Age: 18-24: 2, 25-34: 7, 35-44: 12, 45+: 4

- Education: high school or less: 6, 1-3 years postsecondary: 4, university degree: 15

- Income: $<\$ 10,000$ per year: $9, \$ 10,000-19,999: 3, \$ 20,000-29,999$ : 5, \$30,000-39,999: 5, \$40,000+: 2

- Employment status: 10 full time, 5 part-time, 7 unemployed, 2 students, 1 disability

- Countries of origin: 9 Mexico, 6 Colombia, 1 or 2 from each from Argentina, Bolivia, Cuba, Nicaragua, Peru, Spain, Venezuela plus one Canadian born of Spanish and Venezuelan parents

- Immigration status: 8 residents, 7 citizens, 8 refugee claimants, 2 refugee status

- Sexual practice in country of origin: sex with men 20 , sex with men and women 3 , sexually inactive 2

Overall then, study participants included significant proportions of modestly and well-educated men, perhaps reflective of Canadian immigration requirements outside of the migrant farm worker program. With a few exceptions, income levels were low. Countries of origin were also generally reflective of Latin American migration patterns to Canada with Mexico and Colombia accounting for a major portion.

\section{Sexuality in Countries of Origin}

The experiences of Latino gay men in their countries of origin reflect the fast changing situation of LGBT people in Latin America that varies significantly by generation and region. Latin America is not exempt from a globalizing world system of international LGBT identities, movements, and civil rights that circulate widely and become cognitive frameworks for understanding desires and relationships. These international signifiers of desire enter local cultures unevenly, sometimes as an overlay adopted more by the young, urban, and well-educated without necessarily displacing longer standing conceptions of gender and sexuality (Altman 2000; Adam 2002). For those originating in metropolitan centres with significant social and economic capital at their disposal-and these are individuals particularly well placed to be accepted under Can- 
adian immigration policy - the transition to Canada and to Canadian gay worlds may be more a question of continuity than dislocation. Several express a cosmopolitan understanding of international gay networks before emigrating and an evolving, rather than transformative, notion of same sex relationships within this larger frame. This man in his 50s with a graduate degree expresses the cosmopolitan vision:

I have had the opportunity to be in the United States several times, to travel to Miami, New York, San Francisco. I've been to Brazil and have had access to computers and so to information.... I've gone back to the gym because I like the idea of how gay men take care of themselves here. They look very masculine and I like that. (50s, postgraduate education, Colombia) (All excerpts translated from Spanish)

Similarly, for men who come from major Spanish speaking cities with well-developed gay scenes, differences seem minor. For immigrants from Argentina and Spain, countries with very similar legal regimes to Canada and well-developed urban gay scenes, differences with Canada are virtually imperceptible:

It's the same, it's exactly the same. (20s, college)

The way of living homosexuality in Canada is exactly the same as in Europe. To say it more generally, it is the same tendency, the same idea of a gay zone, the same idea of the gay bar, the same idea of gay interaction. (40s, university)

The narratives of the urban, educated classes further erode the imposition of a traditional-vs-modern distinction on Latin America as many speak of active participation in gay scenes (ambiente gay) and even with gay student clubs at universities, Pride celebrations, or movement organizations. This individual in his 30 s with a graduate degree remarks,

When I came out of the closet and was going to bars and gay entertainment venues like cafes, saunas, videos, and such, I never participated in Pride in Colombia, but before coming here, I had a foundation that supported the rights of LGBT people.

And another from a different South American country concurs,

Well I was going to the gay neighbourhood, to discos, bars, and participating in different discussions or groups specifically for gay people. (30s, postgraduate) 
This cosmopolitan, well-educated migrant varies somewhat from the portrait of Latinos more common in the US research literature perhaps because of Canadian immigration policy which tends to select individuals with considerable economic and cultural capital through regular immigration channels, but also because of the rapidly growing urban gay scenes that have become increasingly visible in places like Mexico City, Bogotá, and Buenos Aires in the early twenty-first century.

\section{Non-METRopolitan Origins}

This apparently seamless transition to Canada, however, is the experience of a comparatively privileged subset of migrants. A social location outside of capital cities provides less access to, awareness of, or engagement with gay scenes because of distance, youth, or personal preferences.

I've been sexually active since I was thirteen.... We were located in a rather conservative provincial city with no openly gay scene. To go out to disco bars, we had to go to neighbouring cities. (40s, university)

Becoming gay involved journeys of self-discovery begun inside, and continuing after, emigration from countries of origin. Leaving home for university was part of a process of widening horizons for several.

Well it all started when I went to university in Bogotá because I knew a lot of people and when you are in a university in a city like Bogotá, you interact with other people. There are more books in a bigger library; you begin to investigate. (30s, postgraduate, Colombia)

I had gay friends in university, I had gay friends exercising in the swim club I went to but I went to gay bars two or three times. When I found out what a gay bar was, I didn't like to dance, I didn't like electronic music. (20s, postgraduate, Mexico)

Non-metropolitan locations created different kinds of perceptions such as awareness of an emergent scene in the country of origin but a sense of disconnection because of problems of public security.

I went out with friends to see movies and such, but was afraid to go to bars. There was always fighting and beatings and such at the exit. (20s, postgraduate, Colombia)

A much stronger sense of transition is evident among men from nonmetropolitan origins who had experienced social change both as his- 
torical change over the life course and personal change associated with moving between societies.

When I told my mom I was gay, she said, "Don't use that word. That word shocks me."...I felt threatened and in danger and it's a feeling I grew up with that definitely marked my life and the lives of anyone who grew up in the 1980s in Mexico.... I didn't feel safe at church, at school, or at home....To arrive in a new place gives you the opportunity to reinvent yourself, to re-label yourself if you want, to re-forge an identity more appropriate to what you always wanted for yourself or that you dreamed of being or that you aspired to be and I feel that Canada is a place that is very suitable for that, given the freedom I say that a lot of people find in this country. (30s, postgraduate, Mexico)

In the beginning, the word 'gay' mortified me. During my childhood and adolescence, I knew from the comments I heard in Colombian society it was badly regarded. I used to associate 'gay' with transvestism, transsexuality, with hair dressing. (30s, postgraduate, Colombia)

Some retained a sense of navigating social worlds out of sync with each other where the notion of gay remained overshadowed by socially embedded notions of gender transgression.

Among family and friends, it used to be that to say, that boy is gay, they imagined he dressed like a woman and prostituted himself in the street. (30s, secondary school, South America)

Men in this sample, then, came from diverse social locations marked by historical, regional, and life course differences. These heterogeneous origins shaped divergent perceptions of transition from the comparatively seamless movement of the urban and well-informed to the more challenging movement of those bridging family upbringing and regional cultures to international formations of sexual culture and identity.

\section{Transitions: Kin Ties}

When asked about kin ties and support, family response to sexual orientation figured in a major way in stories about engagement with kin. Men in this study and their families sometimes arrived at mutual accommodations ranging from denial or silence to tacit acknowledgement, and in the case of explicit coming out, from acceptance to a break in relations. These family arrangements often set the tone for their subsequent sense of the reliability of kin ties in the migration process and in engagement with kin after arrival. These sometimes tentative and qualified relation- 
ships stand in marked contrast with the intense, almost daily, transnational kin relationships documented among heterosexual Latino migrants in southern Ontario (Cachon 2013). In a few instances, these kin ties were bolstered by family members' reliance on the migrant's ability to transfer financial support back home.

For some men, family relations before migration settled into a "don't ask, don't tell" pattern of tacit acknowledgement.

I have a certain age, I'm still single living with a boy, with a person of the same sex, and two plus two equals four. My family hasn't had the need to want to know because really I continue to be the same. (40s, university)

The non-discussability of sexual orientation may be grounded, especially among young men without a foothold in employment, in a fear of the power that fathers can wield to enforce patriarchal discipline.

If I told my dad that I'm gay, my dad, obviously given his machismo and his way of thinking, is going to cut off all support possible. (20s, some college, Colombia)

Others had weathered a coming out process that ultimately resolved into a new family equilibrium or acceptance.

My mom didn't change in the least. Instead of asking me, "How is your girlfriend?" ... and "Why don't you have a girlfriend?"-I had a girlfriend in grade school—sometimes asks me, "How is [partner]?" My dad knows and my relationship with him hasn't changed at all but he avoids the topic. (20s, postgraduate, Mexico)

I told my mom and dad everything.... I cried and told them, "I am gay and like men and it's not your fault." ...The following day it was as if nothing had happened or that they hadn't accepted it, but from that moment on, they relaxed. It was as if the ice was broken...I came with my partner and he [dad] had no problem, gave him a kiss on the cheek. (30s, postgraduate, Caribbean)

On a tolerance scale from 1 to 10 , my mom is now an 8 . The two remaining points from a 10 are a question of religion. (30s, postgraduate, Colombia)

Not all were so fortunate to meet family acceptance.

My mom found out because she found a letter that I had sent to a boy and had hidden.... They stopped all financial support...There were a lot of problems. The truth is I separated from my family. (20s, high school, Mexico) 
Others waited until after their arrival in Canada and after acquiring a means of supporting themselves before risking familial disapproval.

I said, "Look, if you are going to come to see me, you have to know that I have a boyfriend and if you would like to know him, I would be very happy to introduce him to you, but if not, I don't want you to do anything nasty," and my mom was still thinking it was all a joke until she arrived and realized that in reality there was a man there who was my boyfriend.... She tried to persuade me that it was wrong, that it was going to be very difficult for me, that it was no way to live, that it would give her a heart attack, all that emotional blackmail.... She returned and didn't talk to me for months and this Christmas didn't talk to me by phone. (30s, postgraduate, Mexico)

These experiences, then, accord with other research into LGBT migration that shows how many have a sense of social dislocation even preceding migration where traditional kin and community ties cannot always be relied on. Combined with major challenges in establishing oneself in a new language and a new economy (Adam and Rangel 2015), this background set the conditions for reconstructing a life in a new country and, in some instances, the desire and need to make new connections.

\section{Transitions: New Relationships}

Given the tenuousness of kin ties and the disruption of prior intimate relationships, the desire to find new connections may be particularly strong. As well, many echo the migratory experience described by Gorman-Murray (2009) and Lewis (2014) insofar as migration represented to them a greater freedom to act openly. Most were actively looking for or engaging in sexual and intimate relationships and succeeding in a number of instances. Fifteen of twenty-five mention having had boyfriends or long-term partners in their home countries. In some instances, migrants arrived as a couple. Some chose to come to Canada because same-sex marriage and relationship recognition were official policy in Canada but not in most other countries including the United States at the time of their migration. More often, migration meant leaving behind social and sexual networks. At the time of the interview, eight were living with roommates, eight with a partner, seven alone, and two with kin. Apart from those who came to Canada as couples, the timing of migration may have been related to the end of a relationship in the home country, it may have stressed an existing relationship, or it may have been viewed as an opportunity to start afresh. 
I had a boyfriend for four or five years more or less and we separated a year before I came here. (30s, postgraduate, Caribbean)

I was living with my partner before coming. In fact, we wanted to come together but at the last minute, he decided not to come and stayed behind.... He found a job that suited him and so did not come. (40s, high school, Mexico)

Many pursued new relationships with some success.

I knew absolutely no English and this guy I saw in the subway...we were eyeing each other. I arrived at my stop and he got off the train as well. He didn't speak Spanish and I didn't understand much...then he got a pen and paper and gave me his name and number and two weeks later...he appeared with his Spanish-English dictionary and it was funny because what he wanted to say, he looked up the word and showed me and when I wanted to say something, I also took his dictionary looking for the word.... We saw each other for about five months. (30s, high school, South America)

Another related meeting a man in a bar who proposed marriage two months later (whom the interviewee then turned down) and yet another was living with a Canadian partner for a year and a half at the time of the interview. Others continued to meet new people, had episodic relationships, or acquired "friends with benefits."

Perhaps the underlying theme is that migration is very often a moment of heightened change in sexual and intimate relationships as well as economic and social relationships. For gay migrants, this change may be greater than for other migrants, given uncertainty about kin ties, leading to a strong need and desire to make to new connections.

\section{LEARNING ABOUT HIV}

Making new connections entails HIV risk management strategies for gay men in the current era. Migrants may have first heard about HIV or AIDS in their country of origin and encountered attitudes of people there toward people with HIV. They may again encounter both information and local attitudes towards HIV in Canada. Most striking in their responses were the generational differences with younger men in their $20 \mathrm{~s}$ and $30 \mathrm{~s}$ reporting significant education about HIV in their home countries, often through institutional sources such as schools, clinics, or AIDS organizations. Older men, who lived through the early panic ridden days of AIDS had received little information of value and often remembered the ideological attacks directed toward gay men and HIV-positive people by 
the press, church, and politicians. In this, Latino gay men lived through a changing historical landscape not unlike that of their counterparts in North America.

For these two men, aged 45 and 51, the typical answer was, "I knew nothing about using a condom in Colombia" and

That was in the beginning when I was seventeen and there wasn't much beyond that it was a disease that gay men had and there wasn't much more until it came out that Rock Hudson had it. I remember nobody knew how it passed from one person to another. (40s, college, Colombia) (Italicized words spoken in English in the original.)

Older men recalled HIV being introduced into the mass media as a scandal and an occasion for attacks on gay men.

I am from the era when those awful pictures of people in the final stages of Kaposi's sarcoma came out. (40s, university, Spain)

The first time I heard of it, I was about fifteen. The newspapers were filled with the pink plague, the illness that killed - because the newspapers were very strong in announcing things and referring to gays, for example, the disease of fags [cabros y maricones] with AIDS. (30s, secondary school, South America)

Several recalled the use of the term pink plague in the press and the mass stigmatization of homosexual men along with a lack of useful information concerning HIV prevention or care.

Younger men in their late 20 s and early 30 s recalled a good deal more, the beginning of information dissemination through institutional sources, and access to testing.

For years in college and my whole life I've heard about it.... but I don't know exactly how to take care of myself... They told us we have an institution, HIV and syphilis tests are free and confidential, you can come, we have condoms, we have a psychologist.... Yes, it's a clinic. (20s, postgraduate, South America)

In the 1980s, I knew there was a disease that caused immunodeficiency and I understood well. When I was in [home country] there were cases and you had to be careful. (30s, postgraduate, Caribbean)

Finally, these men noted a change in HIV education over time, and even younger men in their early 20 s recall formal instruction about HIV in school or local AIDS service organizations. The youngest man in this sample recalls being taught about HIV in grade 8 or 7 and others from 
different countries heard about HIV in sex education classes as early as grade 6 , though this information was rarely gay-friendly.

There was a lot all over when I was in college and in university too, there were seminars, education, TV...What I know about in Colombia are pamphlets and cards for homosexuals in the bars and websites but there was no commercial that came out as I've seen here. (30s, postgraduate, Colombia)

A significant portion of the study participants remarked that their awareness of HIV was related to the seroconversion of someone they knew, or because they seroconverted themselves. Two interviewees from different countries stated that these experiences led them to work with or volunteer with AIDS service organization in their countries of origin.

In 84 or $83 . .$. everybody in Mexico was talking about the disease of putos, of homosexuals. I said, "What's that?" Then I began to know friends who were ill, friends that were dying. I joined. (30s, postgraduate, Mexico)

In short, the HIV environment changed rapidly over a few decades with older men, who passed through the early years of the epidemic in home countries, recalling days of panic and persecution and younger men commenting that they had been educated about HIV risk in school, through personal networks, and AIDS organizations.

\section{HIV Risk Management}

Study participants were also asked to talk about recent sexual encounters. If sex without a condom did not come up spontaneously, they were asked about the circumstances in which their last occasion of condomless sex occurred. For some, their answer was that they consistently practised safe sex. For this respondent, living through the worst days of the HIV epidemic shaped his commitment to protected sex.

A lot of people died of AIDS. They were people who had a lot of sex, went to saunas and places for easy sex... and unfortunately they contracted the illness. It affected me a lot because they were people very close to me, people with a future, people who wanted to live and who had plans and the disease took them. (40s, university, Spain)

For another, migration did not alter a well-established practice.

I always use a condom, always. As much in Colombia as here I've always used a condom. (50s, postgraduate, Colombia) 
Represented in this sample were several men in relationships of some duration for whom HIV risk management had been resolved with a sexually exclusive relationship.

At first we took care but later when we became more than boyfriends, we moved in together and all that, we decided to be a monogamous couple so we changed because of that. (20s, college, South America)

Others described situations when infrequent "slip ups" occurred sometimes due to the "heat of the moment" or an inadvertent condom break.

Once we had sex and he was so excited and I was so excited that we didn't realize the condom had broken. (30s, postgraduate, Colombia)

Still others describe situational factors that are well established in the HIV research literature such as trust formation or depression as precursors to unprotected sex.

This rather conventional set of experiences associated with condomless sex is perhaps not surprising given that similar findings are common among broad-based studies of gay men in general when "high risk" men are not specifically recruited for study. A parallel study of gay men who had recently tested HIV-positive, also conducted by the lead author and principal investigator of this study, did encounter a few Latino men who come closer to the model identified by Egan (2011) and colleagues.

I'm somebody who experienced all the drugs...for sex. So that helped me to understand more about my sexuality.... When I got infected I was really feeling very lonely and I got in this sexual addiction, I think, combined with crystal and just having sex with different guys.... I was not feeling any connection with anybody. So every weekend I was going to these clubs and after the bathhouse..... My drug story started in 2005 here and after I broke up with my second boyfriend. So I experienced being attractive and having all this success with these guys and like being in this drug thing and having a lot of sex and just checking my list of all the hottest guys I have like you know and validating myself I think. (Author 2013)

Here the search for new social and sexual connections following migration led to engagement with drug networks and a pattern of unprotected encounters.

\section{Conclusion}

Research on sexual health and migration in the United States has raised several hypotheses on how to account for the small, but statistically sig- 
nificant, higher rates of HIV among Latinos as measured by broad-based epidemiological surveillance. Research indicators suggest that a similar trend may also be present in Canada. These qualitative interviews offer a glimpse into the complexity of the backgrounds, transitions, and relationships of Spanish-speaking gay and bisexual men in Canada in relation to HIV risk. With a relatively small, unsystematic sample, only tentative conclusions are warranted: for the most part, the Spanishspeaking gay and bisexual men interviewed here show a similar profile to Canadian-born men in that they have strong generational differences in HIV experience. Younger men report considerable HIV education in their home countries before arriving in Canada and appear, as well, to have a high awareness of HIV while in Canada. Many arrive with significant social, educational, and economic capital though they may find themselves un(der)employed and un(der)paid after arrival. This sample shows many of the same traits of risk and protection shared by other gay and bisexual men in Canada and elsewhere, with behaviour ranging from consistent safe sex, to inadvertent "slips." More consistent patterns of unprotected sex show some of the same social conditions identified in the current research literature for gay men in several countries.

Migration may nevertheless enter into the mix of conditions by exacerbating social and economic vulnerability. While the migration research literature tends to document the centrality of kin in the migration process, among gay men participating in this study, kin ties could be less confidently relied on compared to their heterosexual counterparts and migration itself may have been associated with strained or broken ties with boyfriends and partners, giving credence to the social disruption thesis as a factor in elevating risk. At the same time, the narratives of these men are broadly consistent with the small research literature on migration among LGBT people which shows migration can work as both a disruption of "home" social networks but also an opening to create new support systems that may come to feel more "home"-like than less hospitable environments of origin.

Finally, in terms of previous research into the globalization of LGBT identities, these interviews suggest that migrants with considerable social capital may arrive with cosmopolitan perceptions, previous contacts with gay worlds, and global discourses about sexuality, and then experience more continuity than difference in moving from major urban areas with developed gay scenes in their home country to Canada's largest city. This sense of continuity is less evident among those originating in small cities or rural areas or with fewer educational and financial resources. This analysis suggests that HIV prevention for immigrant gay and bisexual men needs to engage with social and cultural capital as medi- 
ators of risk, and to engage with a range of social determinants of health to support this population.

\section{ACKnowledgements}

This work was made possible with the assistance of Gerardo Betancourt, Nelson Cabral, Alberto Carneiro, Andre Ceranto, Miguel Cubillos, Marco Gomes, Samuel Lopez, Sergio Martinez, Marco Paolinelli, Marco Posadas, Carlos Rivas and Angel Serrano, and with the support of a Career Scientist Award in Risk, Culture and Sexuality provided by the Ontario HIV Treatment Network.

\section{REFERENCES}

Adam, Barry D. 2002. Theorizing the globalization of gay and lesbian movements. Research in Political Sociology 10:123-137.

Adam, Barry D, Gerardo Betancourt, and Angel Serrano Sánchez. 2011. Development of an HIV prevention and life skills program for Spanish speaking gay and bisexual newcomers. Canadian Journal of Human Sexuality 20 (1):11-17.

Adam, Barry D, Winston Husbands, James Murray, and John Maxwell. 2008. Circuits, networks, and HIV risk management. AIDS Education and Prevention 20 (5):420-435.

Adam, Barry D, and J Cristian Rangel. 2015. The post-migration sexual citizenship of Latino gay men in Canada. Citizenship Studies 19 (6-7):682-695.

Althoff, Meghan, Colin Anderson-Smits, Stephanie Kovacs, Oscar Salinas, John Hembling, Norine Schmidt, and Patricia Kissinger. 2013. Patterns and predictors of multiple sexual partnerships among newly arrived Latino migrant men. AIDS and Behavior 17:2416-2425.

Altman, Dennis. 2000. Global Sex. Chicago: University of Chicago Press.

Arreola, Sonya, George Ayala, Rafael Díaz, and Alex Kral. 2013. Structure, agency, and sexual development of Latino gay men. Journal of Sex Research $50(3-4): 392-400$.

Basok, Tanya. 2004. Post-national citizenship, social exclusion and migrants rights. Citizenship Studies 8 (1):47-64.

Betancourt, Gerardo. 2011. Guys like you: The fotonovela and the website, In Minorités sexuelles, internet et santé, edited by Joseph Lévy, Jean Dumas, Caitlin Ryan and Christine Thoër. Québec: Presses de l'Université du Québec. 
Bruce, Douglas, Gary Harper, and Adolescent Medicine Trials Network for HIV/ AIDS Interventions. 2011. Operating without a safety net. Health Education and Behavior 38 (4):367-378.

Cachon, Maria Frances. 2013. Embodied cartographies of Mexican-Canadian transnationalism, Sociology, University of Windsor, Windsor, Ontario.

Cantu, Lionel. 2009. The Sexuality of Migration. New York: New York University Press.

Carrillo, Hector. 2004. Sexual migration, cross-cultural sexual encounters, and sexual health. Sexuality Research \& Social Policy 1 (3):58-70.

Centers for Disease Control and Prevention. 2017. HIV among Hispanics/Latinos: Centers for Disease Control and Prevention.

De Maio, Fernando, and Eagan Kemp. 2010. The deterioration of health status among immigrants to Canada. Global Public Health 5 (5):462-478.

Díaz, Rafael. 1998. Latino Gay Men and HIV. New York: Routledge.

Díaz, Rafael, George Ayala, and Edward Bein. 2004. Sexual risk as an outcome of social oppression. Cultural Diversity and Ethnic Minority Psychology 10 (3):255-267.

Díaz, Rafael, George Ayala, Edward Bein, Jeff Henne, and Barbara Marin. 2001. The impact of homophobia, poverty, and racism on the mental health of gay and bisexual Latino men. American Journal of Public Health 91 (6):927-932.

Egan, James, Victoria Frye, Steven Kurtz, Carl Latkin, Minxing Chen, Karin Tobin, Cui Yang, and Beryl Koblin. 2011. Migration, neighborhoods, and networks. AIDS and Behavior 15:S35-S50.

EMIS Network. 2013. The European Men-Who-Have-Sex-With-Men Internet Survey. Findings from 38 countries. Stockholm: European Centre for Disease Prevention and Control.

Fontdevila, Jorge. 2009. Framing dilemmas during sex. Social Theory and Health 7:241-263.

Fortier, Anne-Marie. 2001. 'Coming home' Queer migrations and multiple evocations of home. European Journal of Cultural Studies 4 (4):405-424.

Gonzalez, Jeffrey, Ellen Hendriksen, Erin Collins, Ron Durán, and Steven Safren. 2009. Latinos and HIV/AIDS. AIDS and Behavior 13:582-602.

Gorman-Murray, Andrew. 2009. Intimate mobilities. Social \& Cultural Geography 10 (4):441-460.

Hammack, Phillip, and Bertram Cohler. 2011. Narrative, identity, and the politics of exclusion. Sexuality Research \& Social Policy 8:162-182.

Knopp, Larry. 2004. Ontologies of place, placelessness, and movement. Gender, Place and Culture 11 (1):121-134. 
Lewis, Nathaniel. 2014. Rupture, resilience, and risk. Health \& Place 27:212219.

2016. Urban encounters and sexual health among gay and bisexual immigrant men. Geographical Review 106 (2):235-256.

Lo, Serena, Carol Reisen, Paul Poppen, Fernanda Bianchi, and Maria Zea. 2011. Cultural beliefs, partner characteristics, communication, and sexual risk among Latino MSM. AIDS and Behavior 15:613-620.

Magis-Rodríguez, C, G Lemp, MT Hernandez, MA Sanchez, F Estrada, and E Bravo-García. 2009. Going north. Journal of Acquired Immune Deficiency Syndromes 51 (Supplement 1):S21-S25.

Muñoz-Laboy, M, D Castellanos, and R Westacott. 2005. Sexual risk behaviour, viral load, and perceptions of HIV transmission among homosexually active Latino men. AIDS Care 17 (1):33-45.

Myers, Ted, Robert Remis, Winston Husbands, Orhan Hassan, Christiane Bouchard, Charles Shamess, Bruce Clarke, Peter Richtig, John Maxwell, Frank McGee, James Murray, Barry D Adam, and Dan Allman. 2011. Lambda Survey: M-Track Ontario second generation surveillance: p. 121. Toronto: Public Health Agency of Canada.

Nakamura, Nadine, and Maria Zea. 2010. Experiences of homonegativity and sexual risk behaviour in a sample of Latino gay and bisexual men. Culture, Health \& Sexuality 12 (1):73-85.

Newbold, K Bruce. 2006. Chronic conditions and the healthy immigrant effect. Journal of Ethnic and Migration Studies 32 (5):765-784.

O'Donnell, Lydia, Gail Agronick, Alexi Doval, Richard Duran, Athi Myint-U, and Ann Stueve. 2002. Ethnic and gay community attachments and sexual risk behaviors among urban Latino young men who have sex with men. AIDS Education and Prevention 14 (6):457-471.

Ontario HIV Epidemiology and Surveillance Initiative. 2017. New HIV diagnoses in Ontario: p. 23. Toronto: Ontario HIV Treatment Network.

Organista, Kurt, Héctor Carrillo, and George Ayala. 2004. HIV prevention with Mexican migrants. Journal of Acquired Immune Deficiency Syndromes 37 (Supplement 4):S227-S239.

Pérez, Daniel. 2011. Entre machos y maricones, In Gay Latino Studies, edited by Michael Hames-García and Ernesto Martínez pp. 147-167. Durham, NC: Duke University Press.

Poppen, Paul, Carol Reisen, Zea, Fernanda Bianchi, and John Echeverry. 2005. Serostatus disclosure, seroconcordance, partner relationship, and unprotected anal intercourse among HIV-positive Latino men who have sex with men. AIDS Education and Prevention 17 (3):227-237.

Ramirez-Valles, Jesus, Lisa Kuhns, Richard Campbell, and Rafael Diaz. 2010. Social integration and health. Journal of Health and Social Behavior 51 (1):30-47. 
Ryan, Caitlin, David Huebner, Rafael Diaz, and Jorge Sanchez. 2009. Family rejection as a predictor of negative health outcomes in white and Latino lesbian, gay, and bisexual young adults. Pediatrics 123:346-352.

Stall, Ron, MS Friedman, and J Catania. 2007. Interacting epidemics and gay men's health, In Unequal Opportunity, edited by Richard Wolitski, Ron Stall and Ronald Valdiserri. Oxford: Oxford University Press.

Statistics Canada. 2017. NHS Focus on Geography Series: Toronto, CMA, Immigration and Ethnocultural diversity, National Household Survey. Ottawa: Statistics Canada.

Zea, Maria, Carol Reisen, Fernanda Bianchi, Felisa Gonzales, Fabián Betancourt, Marcela Aguilar, and Paul Poppen. 2013. Armed conflict, homonegativity and forced internal displacement. Culture, Health \& Sexuality 15 (7):788-803.

Barry D Adam is Distinguished University Professor, Sociology, Anthropology \& Criminology University of Windsor. He works with researchers, policymakers, and community-based organizations in building capacity in effective interventions for HIV prevention. With an extensive background of communitybased research into HIV prevention and issues of living with HIV, Barry works with community research teams in a number of areas. He is the editor author of the 1987 book The Rise of a Gay and Lesbian Movement, and later editor of The Global Emergence of Gay and Lesbian Politics.

E-Mail: adam@uwindsor.ca

J. Cristian Rangel is a PhD student in the Department of Sociology, UofT. His dissertation studies how physicians' humanitarian and advocacy work for refugee care and non-status immigrants influence human rights and political discourse in Canada and Spain.

E-Mail: cristian.rangel@mail.utoronto.ca 